\title{
Costa Rica sin Fronteras
}

Pensar en Movimiento:

Revista de Ciencias del Ejercicio y la Salud

ISSN 1659-4436

Vol. 12, No.1, pp. 1-4

\section{COSTA RICA SIN FRONTERAS \#9}

En esta sección se publican los resúmenes en español de artículos que han sido publicados por investigadoras/es de universidades costarricenses en otras revistas en el mundo, con su debida referencia al trabajo original, y con una breve explicación de dónde se realizó la investigación. Los artículos originales han sido publicados en otros idiomas; las revistas tienen consejo editorial y manejan un proceso de revisión por pares.

Los resúmenes corresponden a estudios relacionados con las ciencias del ejercicio y la salud, que se conforman a los criterios generales de la revista, esto es, se trata de "... estudios experimentales o que hagan recomendaciones concretas para solucionar problemas 0 preguntas relevantes (...) trabajos originales o de meta-análisis." Solicitamos a las personas que han publicado este tipo de trabajos en otros idiomas que no los hagan saber, para incluir sus resúmenes aquí. 


\title{
Efecto de un programa de hidrogimnasia en los niveles séricos de Proteína C reactiva de alta sensibilidad en mujeres adultas mayores
}

Hall-López, J. A., Ochoa-Martínez, P. Y., Alarcón-Meza, E. I., Anaya-Jaramillo, F. I., Teixeira, A. M. M. B., Moncada-Jiménez, J. A., Ferreira Reis, J.C., \& Dantas, E. H. M. (2014). Effect of a hydrogymnastics program on the serum levels of high-sensitivity C-reactive protein amongst elderly women. Health, 6(1), 80-85. Retrieved from:

http://www.scirp.org/journal/PaperInformation.aspx?PaperlD=41767\&\#.U6pit5R5Ngo

El objetivo del estudio fue evaluar el efecto de un programa de entrenamiento de hidrogimnasia en los niveles de Proteína $C$ reactiva de alta sensibilidad (PCR-as) en mujeres adultas mayores. Los sujetos fueron asignados aleatoriamente en un grupo experimental que participó en el programa de hidrogimnasia, y un grupo de control, que no participó en el entrenamiento y permaneció sedentario. Los niveles en suero de PCR-as se determinaron mediante inmunoturbidimetría utilizando proteína C reactiva (PCR). El protocolo de entrenamiento consistió en sesiones de hidrogimnasia realizadas 5 veces por semana durante 12 semanas de intervención, ejecutados en una piscina de 1.3 metros de profundidad y divididos en tres fases: un precalentamiento de $10 \mathrm{~min}, 30 \mathrm{~min}$ de ejercicio aeróbico al $50-60 \%$ de la frecuencia cardiaca máxima (controlado por un monitor de ritmo cardíaco), y 10 min de enfriamiento. Se utilizó el análisis de varianza (ANOVA) 2 x 2 (grupo x medición) como método estadístico para comparar los resultados entre los grupos en las variables pre y post entrenamiento utilizando el programa SPSS, versión 17. Los hallazgos indicaron cambios significativos en el nivel de PCR-as, y un mayor porcentaje de disminución de la PCR-as $(\Delta \%=-37 \%, p=0.001)$ en el grupo experimental respecto al grupo control. Por lo tanto, se puede inferir que un programa de hidrogimnasia es eficaz en la reducción de la tasa metabólica de PCR-as en mujeres adultas mayores.

Este estudio se realizó con el fondo concursable obtenido en la convocatoria de la Asociación Nacional de Universidades e Instituciones de Educación Superior (ANUIES) de México y el Consejo Superior Universitario Centroamericano (CSUCA). Colaborador: José Moncada Jiménez.

La revista Health reporta un factor de impacto ISI Web of Knowledge de 0.16 (año 2013).

\author{
(c) (1) $(9$ \\ Esta obra está bajo una \\ licenciaCreativeCommons Atribución-NoComercial-SinDerivadas 3.0 Costa Rica.
}




\section{El efecto de diversas actividades físicas y deportivas en la imagen corporal de estudiantes universitarios costarricenses}

Chacón-Araya \& Moncada-Jiménez, J. (2013). The effect of different physical and sport activity courses on the body image of Costa Rican students. Journal of Physical Education and Sport, 13(4), 498-503. Retrieved from: http://efsupit.ro/images/stories/nr4.2013/Art\%2078.pdf

El propósito de este estudio fue determinar el efecto de diferentes tipos de cursos de actividad deportiva sobre la imagen corporal percibida y deseada en estudiantes de la Universidad de Costa Rica. Participaron voluntariamente 522 alumnos (259 mujeres y 263 hombres), matriculados en 13 diferentes cursos de actividad deportiva, a partir de los cuales se construyeron dos categorías: a) deportes y b) acondicionamiento físico. A los sujetos se les realizaron mediciones corporales (estatura, peso y circunferencia de la cintura) y con los valores de la talla y peso se calculó el índice de masa corporal (IMC). Luego se les suministró la escala de imagen corporal de Thompson y Gray (1995) la primera, segunda y última semana de clases. Los resultados indicaron que no existían interacciones significativas en la imagen corporal independientemente del sexo ni de los diferentes cursos de actividad deportiva. Se encontró que las mujeres presentaron un \% de grasa mayor que los hombres $(p<0.01)$, y que la circunferencia de la cintura en ellas aumenta ligera, pero significativamente en comparación con la de los hombres, desde el pre-test hasta el post-test $(p<0.05)$. Se halló que las personas con mayor \% de grasa corporal también presentaban una mayor insatisfacción corporal $(r=-0.13, p<0.01)$. En conclusión, no existe un efecto del tipo de actividad deportiva o de acondicionamiento físico en la imagen corporal de estudiantes universitarios, pero se debe poner especial atención a las personas con mayor grado de adiposidad pues muestran mayor insatisfacción con su imagen corporal.

Este estudio fue inscrito en la Vicerrectoría de Investigación de la Universidad de Costa Rica con el número B0322. Colaborador: José Moncada Jiménez.

La revista Journal of Physical Education and Sport no reporta un factor de impacto.

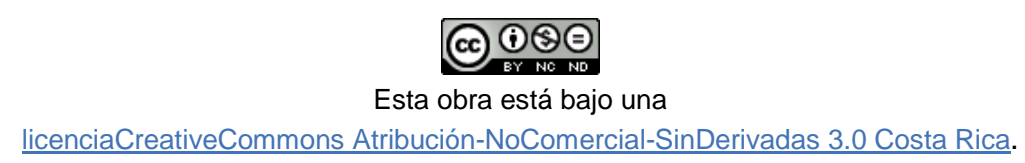




\section{Validez y confiabilidad de la Plataforma de Equilibrio Nintendo $\mathrm{Wii}^{\circledR}$ para valorar el equilibrio de pie y la integración sensorial en adultos mayores altamente funcionales}

Scaglioni-Solano, P., and Aragón-Vargas, L.F. (2014). Validity and reliability of the Nintendo Wii Balance Board to assess standing balance and sensory integration in highly functional older adults. International Journal of Rehabilitation Research 37(2):138-143. doi: 10.1097/MRR.0000000000000046. Retrieved from:

http://journals.Iww.com/intjrehabilres/Abstract/2014/06000/Validity and reliability of the Nint endo Wii.7.aspx

El equilibrio en bipedestación es una actividad motriz importante. La inestabilidad postural asociada con la edad es un resultado común del deterioro de los sistemas sensoriales periféricos. En este estudio se utilizaron el Test Clínico de Integración Sensorial del Equilibrio (modificado) y la prueba de tándem para analizar el equilibrio. Las pruebas cronometradas presentan ciertas limitaciones, mientras que la cuantificación de los movimientos del centro de presión (CdP) mediante herramientas portátiles y económicas puede aumentar la sensibilidad de dichas pruebas y facilitar que se generalice su uso. El objetivo de este estudio fue determinar la validez y la fiabilidad de la Plataforma de Equilibrio Wii (PE Wii) con el fin de cuantificar los movimientos del CdP durante las pruebas mencionadas anteriormente. Treinta y siete adultos de edad avanzada realizaron tres repeticiones de las siguientes cinco condiciones de equilibrio: ojos abiertos, ojos cerrados, ojos abiertos en una superficie flexible, ojos cerrados en una superficie flexible y postura en tándem, todos ellos llevados a cabo en una plataforma de fuerza y en una PE Wii de forma simultánea. Veinte participantes repitieron las pruebas para garantizar la máxima fiabilidad. El desplazamiento del CdP fue la variable principal. El análisis de regresión indicó que la PE Wii presenta una validez simultánea excelente, y los gráficos de Bland-Altman mostraron una buena concordancia entre aquellos dispositivos con pequeñas diferencias medias y sin relación entre la diferencia y la media. Los coeficientes de correlación intraclase $(\mathrm{CCl})$ indicaron una fiabilidad test retest de moderada a excelente $(\mathrm{CCl}=0,64-0,85)$. El error estándar de las mediciones y el cambio mínimo detectable fueron similares en ambos dispositivos, excepto para la condición de "ojos cerrados", que presentó un error estándar de medición mayor en la PE Wii. En conclusión, se demostró que la PE Wii constituye un método válido y fiable para cuantificar el desplazamiento del CdP en adultos de edad avanzada.

Este estudio fue inscrito en la Vicerrectoría de Investigación de la Universidad de Costa Rica con el número B1610. Colaborador: Pietro Scaglioni Solano.

La revista International Journal of Rehabilitation Research reporta un factor de impacto de 1.055. 